\title{
Neospora caninum en llamas de Huancavelica, Perú
}

\author{
Neospora caninum in llamas of Huancavelica, Peru \\ Marelsy Pilco $^{1}$, Enrique Serrano-Martínez ${ }^{1,2}$
}

\section{Resumen}

El objetivo del presente estudio fue determinar, mediante la técnica de Inmunofluorescencia Indirecta (IFI), la frecuencia de anticuerpos frente a Neospora caninum en llamas de la comunidad ganadera de Lachocc, Huancavelica. Se tomó muestras de sangre de 98 llamas hembras adultas, mayores de un año. Los sueros se analizaron mediante IFI empleando un punto de corte de 1:100. Los sueros positivos fueron titulados con diluciones seriadas, determinándose una frecuencia de anticuerpos frente a $N$. caninum de 12.2\% (12/98). De los 12 sueros positivos, el 75.0\% (9) presentaron títulos de 1:100, el $16.7 \%$ (2) con $1: 200$ y el 8.3\% (1) con 1:400. No se encontró asociación significativa entre las variables edad, antecedentes de abortos y número de partos con la presentación de serorreactores a $N$. caninum.

Palabras clave: neosporosis; camélidos sudamericanos; inmunofluorescencia; problemas reproductivos

\section{Abstract}

The aim of this study was to determine, through the Indirect Immunofluorescence (IFAT) technique, the frequency of antibodies against Neospora caninum in llamas from the Livestock Association of Lachocc, Huancavelica. Blood samples were taken from 98 adult female llamas, older than one year. The sera were analysed by IFAT using a cut-off point of 1:100. The positive sera were titrated with serial dilutions, determining a frequency of antibodies against $N$. caninum of $12.2 \%(12 / 98)$. Of the 12 positive sera, $75.0 \%(9)$ had titres of $1: 100,16.7 \%(2)$ with $1: 200$ and $8.3 \%$ (1) with $1: 400$. No significant association was found between the variables age, history of abortions and parity with the presentation of seroreactors to N. caninum.

Key words: neosporosis; South American camelids; immunofluorescence; reproductive problems

${ }^{1}$ Grupo SANIVET, Facultad de Medicina Veterinaria y Zootecnia, Universidad Peruana Cayetano Heredia, Lima, Perú

${ }^{2}$ E-mail: enrique.serrano@upch.pe

Recibido: 9 de febrero de 2018

Aceptado para publicación: 27 de julio de 2018 


\section{INTRODUCCIÓN}

Los camélidos sudamericanos (CSA) forman parte de la región andina, cuya fuente de fibra y carne beneficia a la población rural andina (Fernández Baca, 2005; Mengoni, 2008). La llama (Lama glama) es el CSA más grande (Wheeler, 1999), cuyo peso adulto llega a $100-120 \mathrm{~kg}$. Es una especie adaptada a las difíciles condiciones ambientales de la zona andina (Fernández Baca, 2005). Las enfermedades en CSA se presentan por agentes infecciosos y parasitarios (Ortiz, 1988; Ameghino y DeMartini, 1991; Martín et al., 2010), incrementándose con el inicio de lluvias que corresponde a los meses de diciembre a marzo (Llanos y Morales, 2012).

Neospora caninum es un parásito intracelular del género Apicomplexa, familia Sarcocystidae (Martín et al., 2010), responsable de la neosporosis. El ciclo de vida de este parásito comprende tres estadios: taquizoitos, bradizoitos y ooquistes (Dubey et al., 2002). N. caninum es cosmopolita y ha sido reportado en bovinos, ovejas, perros, ciervos de cola blanca, búfalos de agua (Dubey y Lindsay, 1996; Dubey et al., 2007) y camélidos (Chávez et al., 2002; Wolf et al., 2005) como hospederos intermediarios.

En el ganado bovino, la neosporosis ocasiona pérdidas económicas por abortos y mortalidad neonatal (Campero, 2002). El perro, el coyote y el dingo son los hospederos definitivos de $N$. caninum, que se infectan al ingerir tejidos quísticos con bradizoitos de los hospederos intermediarios. A nivel intestinal se desarrolla la fase sexual del parásito, el cual es eliminado con las heces en forma de ooquistes (Dubey et al., 2007). Estos esporulan en 24 horas tornándose infectivos (Dubey et al., 2002), contaminando el agua y los pastos. Los herbívoros, al ingerir el alimento contaminado, desarrollan la fase asexual del parásito (taquizoitos), que invaden diversos órganos causando lesiones, así como su transmisión al feto en hembras gestantes y posterior formación de quistes tisulares (bradizoitos) en el sistema nervioso central, médula y músculos (Dubey, 2003; Dubey et al., 2007).

En 2004, Serrano-Martinez et al. (2004) confirmaron la presencia de $N$. caninum en fetos de alpacas y llamas en el Perú mediante la técnica de PCR e inmunohistoquímica. Otras técnicas serológicas de diagnóstico en animales adultos para la detección de anticuerpos de este parásito son la Inmunofluorescencia Indirecta (IFI) y el Ensayo por Inmunoabsorción Ligado a Enzimas (ELISA) (Dubey, 2003).

La prevalencia de la neosporosis en bovinos se ha reportado en varios países, Así en Brasil fue de $14.09 \%$ (Gondim et al., 1999), Taiwan de 44.9\% (Ooi et al., 2000), Argentina de $9.9 \%$ (More et al., 2008), Uruguay de $61.3 \%$ (Dubey et al., 2007), detectados en todos los casos mediante la prueba de IFI. En cuanto a la prevalencia en camélidos, Chávez et al. (2002) reportaron una frecuencia para la sierra central del Perú de $42.4 \%$ (39/92) en alpacas y $18.4 \%$ (39/212) en llamas, en tanto que Casas et al. (2006) encontraron una frecuencia reducida de $2.9 \%$ $(5 / 175)$ en llamas de la empresa Sociedad Agraria de Interés Social (SAIS), en Junín.

Las llamas desempeñan un rol importante en la economía y alimentación de los pobladores de Huancavelica, Perú, pero se ven afectados por los constantes problemas reproductivos desconociendo el verdadero estatus de la problemática. Es por ello que el objetivo del estudio fue determinar el porcentaje de llamas de la comunidad ganadera de Lachocc, Huancavelica, con anticuerpos frente a Neospora caninum mediante la técnica de Inmunofluorescencia Indirecta.

\section{Materiales Y MéTodos}

El estudio se llevó a cabo en la Comunidad Ganadera de Lachocc, localizada en el distrito de Huancavelica, departamento de 
Huancavelica, a una altitud de $4450 \mathrm{msnm}$. La zona posee una temperatura anual promedio de $10.3{ }^{\circ} \mathrm{C}$ (SENAMHI, 2016). Las muestras fueron procesadas en el Laboratorio de Parasitología Animal de la Facultad de Medicina Veterinaria y Zootecnia de la Universidad Peruana Cayetano Heredia, Lima.

El tamaño de la muestra fue determinado mediante el empleo de la fórmula para proporciones en poblaciones finitas (Morillas, 2007), obteniendo 44 llamas hembras como tamaño mínimo de muestra, considerando un tamaño de población de 4261 animales (INEI, 2012), un nivel de confianza de $95 \%$, una proporción previa de $2.9 \%$ (Casas et al., 2006) y una precisión de 0.05 , al considerar únicamente llamas hembras, mayores o iguales de un año.

La colección de muestras se realizó entre los meses de agosto y noviembre de 2016 en coordinación con los ganaderos de la estancia de la comunidad de Lachocc. Las muestras de sangre fueron colectadas mediante punción directa de la vena yugular en tubos Vacutainer ${ }^{\circledR}$ estériles. Las muestras fueron centrifugadas a $1200 \mathrm{~g}$ por $5 \mathrm{~min}$ para obtener las muestras de suero, los cuales fueron conservados en congelación hasta su procesamiento. En forma adicional, se levantó información situacional y epidemiológica de los animales muestreados considerando los antecedentes de abortos, edad, número de partos y mortinatos en pariciones anteriores.

Los sueros fueron analizados mediante la técnica de IFI descrita por Buxton (1998) por ser una prueba idónea para la detección de rebaños infectados (Dubey et al., 2007), y que no presenta reacciones cruzadas con otros protozoos del Phylum Apicomplexa (Dubey y Lindsay, 1996). Se usó una dilución de 1:100, utilizando como antígeno a taquizoítos formalizados $\left(10^{7} / \mathrm{ml}\right.$ taquizoítos, cepa SPAIN 7), y conjugado comercial antiIgG llama (VMRD, EEUU). Se consideró como suero positivos y negativos a sueros de llamas de Huancavelica, positivos y negati- vos a anticuerpos contra Neospora, confirmado por Western Blotting.

Los sueros positivos fueron titulados. Se usaron láminas de 18 pocillos para IFI fijados con taquizoitos de $N$. caninum, realizando diluciones de 1/100, 1/200, 1/400, 1/800, 1/1600 y $1 / 3200$. Se consideró animales positivos con un título de anticuerpos anti-Neospora igual o mayor a 1:100 (Chávez-Velásquez et al., 2014).

Los resultados de frecuencias fueron expresados en forma porcentual con un nivel de confianza de 95\% (Thrusfield, 1990). Las variables edad, procedencia, número de partos y presencia de anticuerpos específicos fueron analizadas por el método de Chi cuadrado para observar su posible asociación con las infecciones parasitarias.

El trabajo de investigación fue aprobado por el Comité Institucional de Ética para Uso de Animales (CIEA) de la Universidad Peruana Cayetano Heredia, con código de inscripción N. ${ }^{\circ} 67200$.

\section{Resultados}

La frecuencia de anticuerpos frente a $N$. caninum en llamas del distrito de Lachocc, Huancavelica, mediante el análisis con la técnica IFI fue de $12.2 \pm 6.5 \%$ (12/98) (Cuadro 1), siendo el mayor porcentaje de positividad en llamas mayores de seis años $(18.7 \%$; 6/32) y el menor en llamas de $2-4$ años $(4.8 \% ; 1 /$ $21)$, pero sin diferencia significativa.

El 46.7\% (7/15) de llamas con antecedentes de aborto fue seropositivo a $N$. caninum, frente al 5.1\% (4/69) sin antecedentes de aborto, no encontrándose diferencia significativa entre estos grupos. Así mismo, las llamas multíparas y primíparas presentaron mayor frecuencia de seropositividad a $N$. caninum ( 13.1 y $13.0 \%$, respectivamente), con respecto a las nulíparas (7.1\%), sin diferencia significativa entre grupos (Cuadro 2). 
Cuadro 1. Frecuencia de llamas seropositivas a Neospora caninum, según grupo etario, del distrito Lachocc, Huancavelica

\begin{tabular}{ccc}
\hline $\begin{array}{c}\text { Edad } \\
\text { (años) }\end{array}$ & $\begin{array}{c}\text { Llamas } \\
(\mathrm{n})\end{array}$ & $\begin{array}{c}\text { IFI positivos } \\
(\%)\end{array}$ \\
\hline $1-2$ & 14 & 7.1 \\
$>2-4$ & 21 & 4.8 \\
$>4-6$ & 31 & 12.9 \\
$>6$ & 32 & 18.7 \\
\hline Total & 98 & $12.2 \pm 6.5$ \\
\hline
\end{tabular}

Cuadro 2. Frecuencia de llamas seropositivas a Neospora caninum, según número de partos, del distrito Lachocc, Huancavelica

\begin{tabular}{ccc}
\hline $\begin{array}{c}\text { Partos } \\
(\mathrm{n})\end{array}$ & $\begin{array}{c}\text { Llamas } \\
(\mathrm{n})\end{array}$ & $\begin{array}{c}\text { IFI positivos } \\
(\%)\end{array}$ \\
\hline Nulípara & 14 & 7.1 \\
Primípara & 23 & 13.0 \\
Multípara & 61 & 12.9 \\
\hline Total & 98 & $12.2 \pm 6.5$ \\
\hline
\end{tabular}

El 75.0\% (9) de las llamas presentaron títulos de $1: 100$, mientras que el $16.7 \%$ (2) y el $8.3 \%$ (1) presentaron títulos de 1:200 y 1:400, respectivamente, no encontrando seropositividad en diluciones igual o superiores a $1 / 800$.

\section{Discusión}

La frecuencia de $N$. caninum en llamas fue de $12.2 \pm 6.5 \%$ mediante la técnica IFI. Resultados relativamente similares han sido encontrados en otros estudios en el país. Así, Moya et al. (2003) reportaron una frecuencia moderada de $16.7 \%$ (46/275) en lla- mas de dos centros de crianza de la provincia de Melgar Puno, a través de IFI con una dilución de 1:50; Casas et al. (2006) muestrearon llamas de la SAIS Pachacútec y mediante la técnica IFI en una dilución de 1:100 reportaron una frecuencia de $2.9 \%$ (5/175). Así mismo, Chávez-Velásquez et al. (2014), utilizando una dilución de 1:50 en muestras de llamas de la sierra central del Perú encontraron una prevalencia del $8.3 \%$ (153/1845).

La mayor ruta involucrada en la transmisión de la neosporosis es la transmisión vertical (Davison et al., 1999), en tanto que el riesgo de contraer la infección aumenta con la edad (Jensen et al., 1999), debido a la posibilidad de mayor exposición con el protozoario (Anderson et al., 2000; Dubey, 2003). Es así que la mayor casuística de neosporosis en este estudio se presentó en las llamas más longevas, aunque sin diferencia significativa entre grupos etarios. Por otro lado, la parición y empadre coincide con la temporada de lluvias en la zona del estudio (SENAMHI, 2016), que aunado a posibles deficiencias en el manejo de los animales podría conllevar al estrés del animal repercutiendo en la respuesta del sistema inmune (Tizard, 1995), favoreciendo la ocurrencia de neosporosis. Quiroz et al. (2011) mencionan que la temperatura fría y húmeda, como las observadas en el presente estudio, condicionan la esporulación y sobrevivencia de los ooquistes, incrementando el riesgo de la infección postnatal.

En el estudio de Pinedo et al. (2014) con vicuñas capturadas en un «Chaku» en el distrito de Paccha, departamento de Junín, no encontraron anticuerpos anti- $N$. caninum en muestras procesadas con la técnica de IFI en una dilución de 1:50; así mismo, indicaron que solo observaron la presencia de zorros cercanos a las vicuñas, y hasta el momento no se ha demostrado a este cánido como posible hospedero de $N$. caninum. En lo que respecta a las llamas de Lachocc se pudo observar la presencia de perros en el centro de producción, que eran alimentados con comida casera y restos de vísceras de los ani- 
males. Esta costumbre propicia la diseminación de la coccidia (Dubey y Lindsay, 1996; Patitucci et al., 2001).

En el presente estudio no se encontró diferencia significativa entre hembras con o sin antecedentes de aborto. Al respecto, Valencia et al. (2009) señala que los camélidos seropositivos a $N$. caninum presentan 3.3 veces mayor riesgo de aborto que las seronegativas. Los títulos encontrados en este estudio resultaron ser bajos, lo que indica posiblemente que los animales del estudio no transitaban por etapas agudas de la infección de $N$. caninum.

\section{Conclusiones}

- La frecuencia de seropositividad contra Neospora caninum en llamas fue moderada: $12.2 \pm 6.5 \%$

- Las variables edad, antecedentes de aborto y número de partos no estuvieron asociadas a la presencia de infecciones por $N$. caninum en las llamas.

- Los títulos de anticuerpos contra $N$. caninum fueron bajos.

\section{Agradecimientos}

Los autores agradecen el financiamiento del estudio a Cienciactiva del CONCYTEC por el apoyo financiero brindado al proyecto «Obtención y caracterización del primer aislado de Neospora caninum causante de abortos en camélidos sudamericanos del Perú, con fines inmunodiagnóstico y vacunal» (Convenio de Gestión N. ${ }^{\circ}$ 220-2015 FONDECYT -De), que permitió los análisis y la capacitación técnica de nuestros investigadores para la ejecución del estudio.

\section{Literatura Citada}

1. Ameghino E, DeMartini J. 1991. El aspecto sanitario en alpacas y ovinos de las comunidades del departamento de Puno. Lima, Perú: IVITA-UNMSM. 89 p.
2. Anderson ML, Andrianarivo $A G$, Conrad PA. 2000. Neosporosis in cattle. Anim Reprod Sci 210: 1169-1172.

3. Buxton D. 1998. Protozoan infections (Toxoplasma gondii, Neospora caninum and Sarcocystis spp.) in sheep and goats: recent advances. Vet Res 29: 289-310.

4. Casas G, Chávez A, Casas E, Leyva V, Alvarado A, Serrano E, Ticona D, et al. 2006. Presencia de Neospora caninum en llamas de una empresa ganadera de la Sierra Central. Rev Inv Vet Perú 17: 8-13. doi: 10.15381/rivep.v17i1.1450

5. Campero CM. 2002. Pérdidas provocadas por Neospora caninum en bovinos. VET-SUY 18. [Internet]. Disponible en: http://www.veterinaria.org/asociaciones/vet-uy/articulos/artic_bov/050/ 0018/bov018.htm

6. Chávez A, Serrano E, Casas E, Ortega LM. 2002. Neospora caninum en camélidos sudamamericanos peruanos. Rev Inv Vet Perú 13: 92-93. doi: 10.15381/rivep.v13i2.7338

7. Chávez-Velásquez A, AguadoMartínez A, Ortega-Mora L, CasasAstos E, Serrano-Martínez E, CasasVelásquez G, et al. 2014. Toxoplasma gondii and Neospora caninum seroprevalences in domestic South American camelids of the Peruvian Andes. Trop Anim Health Pro 46: 11411148. doi: 10.1007/s11250-014-0618-1

8. Davison HC, Otter A, Trees AJ. 1999. Estimation of vertical and horizontal transmission parameters of Neospora caninum infections in dairy cattle. Int $\mathrm{J}$ Parasitol 29: 1683-1689. doi: 10.1016/ S0020-7519(99)00129-0

9. Dubey JP. 2003. Review of Neospora caninum and neosporosis. Korean J Parasiol 41: 1-16. doi: 10.3347/ kjp.2003.41.1.1

10. Dubey J, Lindsay D. 1996. A review of Neospora caninum and neosporosis. Vet Parasitol 67: 1-59.

11. Dubey JP, Barr BC, Barta JR, Bjerkas $I$, Björkman $C$, Blogburn BL, Bowman DD, et al. 2002. Redescription 
of Neospora caninum and its differentiation from related coccidia. Int $\mathrm{J}$ Parasitol 32: 929-946. doi: 10.1016/ S0020-7519(02)00094-2

12. Dubey JP, Schares G, Ortega-Mora LM. 2007. Epidemiology and control of neosporosis and Neospora caninum. Clin Microbiol Rev 20: 323-367. doi: 10.1128/CMR.00031-06

13. Fernández Baca S. 2005. Situación actual de los camélidos sudamericanos en Perú. Proyecto de cooperación técnica en apoyo de la crianza y aprovechamiento de los camélidos sudamericano en la Región Andina TCP/RLA/2914. Santiago de Chile: FAO. 63 p.

14. Gondim LF, Sartor IF, Hasegawa M, Yamane I. 1999. Seroprevalence of Neospora caninum in dairy cattle in Bahia, Brazil. Vet Parasitol 86: 71-75. doi: 10.1016/S0304-4017(99)00129-6

15. [INEI] Instituto Nacional de Estadística e Informática. 2012. IV censo Nacional Agropecuario 212. [Internet]. Disponible en: http://proyectos.inei.gob.pe/web/DocumentosPublicos/ ResultadosFinalesIVCENAGRO.pdf

16. Jensen AM, Björkman C, Kjeldsen AM, Wedderkopp A, Willadsen C, Uggla A, Lind P. 1999. Associations of Neospora caninum seropositivity with gestation number and pregnancy outcome in Danish dairy herds. Prev Vet Med 40: 151-163. doi: 10.1016/S01675877(99)00048-3

17. Llanos T, Morales M. 2012. Sanidad y salud animal en camélidos. FAO-Bolivia. [Internet]. Disponible en: http:// www.fao.org/3/a-as961s.pdf

18. Martín C, Pinto CE, Cid MD. 2010. Camélidos sudamericanos: estado sanitario de sus crías. Rev Complu Cienc Vet 4: 37-50.

19. Mengoni GL. 2008. Camelids in ancient Andean societies: a review of the zooarchaeological evidence. Quatern Int 185: 59-68. doi: 10.1016/j.quaint.2007.-05.022
20. Morillas A. 2007. Muestreo en poblaciones finitas. España. 30 p. [Internet]. Disponible en: http://webpersonal.uma.es/ morillas/muestreo.pdf

21. Ooi HK, Huang CC, Yang CH, Lee SH. 2000. Serological survey and first finding of Neospora caninum in Taiwan, and the detection of its antibodies in various body fluids of cattle. Vet Parasitol 90: 47-55. doi: 10.1016/S03044017(00)00211-9

22. Ortiz S. 1988. Evaluación de algunos métodos de control de la mortalidad en crías de alpaca (Lama paccos) en explotaciones familiares. Tesis de Médico Veterinario Zootecnista. Lima: Univ. Nacional Mayor de San Marcos. 45 p.

23. Pinedo K, Chávez A, Rivera H, Pinedo R, Francisco V. 2014. Frecuencia de Toxoplasma gondii y Neospora caninum en vicuñas (Vicugna vicugna) de la sierra central peruana mediante las técnicas de inmunofluorescencia indirecta y ELISA indirecta. Rev Inv Vet Perú 25: 70-76. doi: 10.15381/rivep.v25i1.8470

24. Quiroz H, Figueroa J, Ibarra F, López $M .2011$. Epidemiología de enfermedades parasitarias en animales domésticos. México: UNAM. 655 p.

25. Serrano-Martínez E, CollantesFernández E, Rodríguez-Bertos A, Casas-Astos E, Álvarez-García G, et al. 2004. Neospora species-associated abortion in alpacas (Vicugna pacos) and llamas (Lama glama). Vet Rec 155: 748749. doi: $10.1136 / v r .155 .23 .748$

26. [SENAMHI] Servicio Nacional de Meteorología e Hidrología del Perú. 2016. Pronósticos climáticos. Disponible en: http://www.senamhi.gob.pe/ include_mapas/_dat_esta_tipo.php? estaciones $=000649$

27. Thrusfield M. 1990. Epidemiología veterinaria. Zaragoza, España:Acribia. $335 \mathrm{p}$.

28. Valencia N, Chávez A, García M, Suárez F, Casas E. 2009. Toxoplasmosis como agente causal de abortos en alpacas. Rev Inv Vet Perú 20: 312-319. doi: 10.15381/rivep.v20i2.-629 
29. Wheeler J. 1999. Patrones prehistóricos de utilización de los camélidos sudamericanos. Bol Arqueol PUCP 3: 297-305.

30. Wolf D, Schares G, Cardenas $O$, Huanca W, Cordero A, Barwald A, Conraths F, et al. 2005. Detection of specific antibodies to Neospora cani- num and Toxoplasma gondii in naturally infected alpacas (Lama pacos) llamas (Lama glama) and vicuñas (Lama vicugna) from Peru and Germany. Vet Parasitol 130: 81-87. doi: 10.1016/ j.vetpar.2005.03.024 